\title{
Prokinetics stimulate the increase of ghrelin in mice
}

\author{
Sagkan-Ozturk A ${ }^{1}$, Demir EA ${ }^{2}$, Ozturk A ${ }^{2}$ \\ Department of Physiology, Faculty of Medicine, Mustafa Kemal University, Hatay, Turkey. \\ demirea@live.com
}

\begin{abstract}
OBJECTIVES: Intestinal motility is regulated by several neurotransmitters and neuropeptides including dopamine and acetylcholine as well as ghrelin. Metoclopramide and domperidone are long-standing treatment options for dysmotility, and erythromycin is suggested in selected patients. In the present study, we aimed to investigate the effects of mentioned prokinetics on ghrelin levels.

METHODS: Serum ghrelin levels were estimated by using enzyme-linked immunoassay following a single administration of domperidone, metoclopramide, or erythromycin.

RESULTS: Our results showed that both antidopaminergic and cholinergic prokinetics increase the circulating ghrelin levels. There was no significant difference between enteral and parenteral control groups. Also, statistical analysis revealed that neither prokinetic was superior to the other in regard to its ghrelin stimulating effect. CONCLUSION: Conclusively, the present study demonstrated that the circulating levels of ghrelin increase by the administration of antidopaminergic and cholinergic prokinetics. Hence, this effect on ghrelin may partly be responsible for the motility-stimulating actions of domperidone, metoclopramide, and erythromycin (Fig. 2, Ref. 39). Text in PDF www.elis.sk.

KEY WORDS: domperidone, erythromycin, ghrelin, metoclopramide, prokinetics.
\end{abstract}

\section{Introduction}

The enteric nervous system (ENS), which regulates the gastrointestinal behavior independently of but in cooperation with the central nervous system (CNS), is the most complex part of the peripheral nervous system. The intrinsic neural cell population is allocated to the myenteric and submucosal plexuses. Dopaminergic neurons reside in both plexuses $(1,2)$ and all five types of dopamine receptors $\left(\mathrm{D}_{1-5}\right)$ have been identified in the gastrointestinal tract (2). Dopamine possesses properties of regulating the intestinal circulation (3) and motility (4). It decreases the motility mainly through $\mathrm{D}_{2}$ receptors $(2,5)$, although $\mathrm{D}_{1}$ receptors seem to gain dominance aborally (6). Hence, it is comprehensible why the drugs acting through $\mathrm{D}_{2}$ antagonism, such as metoclopramide and domperidone, bear a net prokinetic effect on the gastrointestinal system (5). These drugs, as well as the cholinergic prokinetic erythromycin, are in clinical use against dysmotility disorders [reviewed by Acosta and Camilleri (7)].

Besides the enteric neurotransmitters, the intestinal motility is under the modulatory control of several neuropeptides. Among these, ghrelin has been identified in 1999 as the ligand for the growth hormone secretagogue receptor (GSH-R1a) (8).

${ }^{1}$ Department of Internal Medicine, Faculty of Veterinary Medicine, Mustafa Kemal University, Hatay, Turkey, and ${ }^{2}$ Department of Physiology, Faculty of Medicine, Mustafa Kemal University, Hatay, Turkey

Address for correspondence: E.A. Demir, Department of Physiology, Faculty of Medicine, Mustafa Kemal University, 31040 Hatay, Turkey. Phone: +90.506 .6709515$

Acknowledgement: This study has been supported by the Mustafa Kemal University Scientific Research Projects Coordination Unit (\#14480).
Ghrelin has been shown to exhibit orexigenic, prokinetic, insulinostatic, adipogenic, vasodilatory, and immunomodulatory properties $(9,10)$. Ghrelin-producing (X/A-like) cells have been located throughout the intestinal tract in rodents, while the stomach is the richest for these cells (11). In physiological conditions, ghrelin levels increase before meals and decrease postprandially, making it to be termed as 'hunger hormone'. However, it is accepted today that this terminology is a result of oversimplification, and ghrelin works as a nutrient-load detector which responds to optimize the energy balance and growth signals (12). As to the particular interest of the present study, ghrelin predominantly recruits extrinsic and intrinsic cholinergic pathways to exhibit its prokinetic effect (13-15). Even so, a recent study by Mondal et al (16) demonstrated the participation of adrenergic (via $\alpha 1$ receptors) and serotonergic (via $5-\mathrm{HT}_{3}$ receptors) neurons. The regulation of ghrelin secretion is a highly intricate process as there are numerous spiraling factors including neurotransmitters and hormones [reviewed by Iwakura et al (17)]. Considering the interaction between dopamine and ghrelin, the medical literature is far from offering a lucid explanation. This is because dopamine has been reported to increase ghrelin levels in the ghrelinoma cell line (18), while neither in vivo (19), nor in vitro (20) effects have been shown in gastric mucosal cells.

In the present study, we aimed to investigate in vivo effects of clinically used dopamine type 2 receptor antagonists, domperidone and metoclopramide, on the levels of circulating ghrelin to see if the dopaminergic regulation occurs via inhibition rather than activation. To compare the effect widths of dopaminergic antagonism, we also used a cholinergic agent, erythromycin, which previously reported to provoke the intestinal motility. 


\section{Materials and methods}

Animals and chemicals

A total of 40 adult ( $>10$ weeks) male Balb/c mice were purchased from the Mustafa Kemal University Application and Research Center for Experimental Researches (Hatay, Turkey). The animals were housed in polycarbonate cages under standardized conditions $\left(22 \pm 2{ }^{\circ} \mathrm{C}\right.$ temperature, $55 \pm 10 \%$ relative humidity, 12:12-h light/dark cycle). Tap water and mouse chow were provided ad libitum. Domperidone (Janssen Pharmaceutica, Belgium) and erythromycin thiocyanate [eq. to $92.54 \%$ (w/w) erythromycin base] (Vetas, Turkey) were ground to fine powder and suspended in distilled water. Metoclopramide (Sifar, Turkey) was obtained as a ready-to-use solution. All experimental procedures were approved by the Local Ethics and Animal Care Committee of Mustafa Kemal University (\#2015/6-6) and performed in accordance with the National Institute of Health Guide for Care and Use of Laboratory Animals (Publication No. 86-23, revised 1996).

\section{Experimental design}

The animals were randomly assigned to five groups as Enteral Control (ECon; $\mathrm{n}=8$ ), Parenteral Control (PCon; $\mathrm{n}=8$ ), Domperidone (Dom; $\mathrm{n}=8$ ), Metoclopramide (Met; $\mathrm{n}=8$ ), and Erythromycin (Eryt; $\mathrm{n}=8$ ). All animals were fasted overnight $(12 \mathrm{~h}$ ) and then given either the vehicle or respective drug depending on which group the animals belonged to. A volume of $0.5 \mathrm{~mL}$ distilled water was orally given to Econ group. Dom and Eryt groups received $20 \mathrm{mg} / \mathrm{kg}$ domperidone and $6 \mathrm{mg} / \mathrm{kg}$ erythromycin thiocyanate, respectively, by oral gavage. PCon animals were intraperitoneally injected with $0.9 \%$ sodium chloride solution $(0.2$ $\mathrm{mL}$ ), while $20 \mathrm{mg} / \mathrm{kg}$, i.p. metoclopramide was administered to the animals in Met group. The animals were anesthetized with $2 \%$ isoflurane in a ventilation chamber immediately before the cardiac puncture to acquire blood. Considering the diverse pharmacokinetics of the drugs, the blood was drawn at time points differing as for the groups: following the drug administration, at 5 th $\mathrm{min}$ for PCon and Met, 15th min for ECon, 30th min for Dom, and 90th min for Eryt. Collected blood was decanted into serum tubes and left to clot for 2 hours at room temperature. Following the centrifugation for 15 minutes at $1000 \mathrm{~g}$, the supernatant was pipetted into microcentrifuge tubes for immunochemical analysis. Active ghrelin levels in the serum were measured by using an ELISA kit (Elabscience Biotechnology, China) following the instructions of the manufacturer. The optical density was measured spectrophotometrically at a wavelength of $450 \mathrm{~nm}$ and ghrelin concentrations (ng/dL) were determined by comparing the optical density of the samples to the standard curve.

\section{Statistical analysis}

Data for enteral treatment groups (ECon vs Dom vs Eryt) were analyzed by one-way ANOVA test followed by post hoc Fisher's least significant difference (LSD) test. The two-tailed unpaired Student's t-test was used for parenteral treatment groups (PCon vs Met) and control groups (ECon vs PCon). The normality of data distribution was determined by using Shapiro-Wilk normality test. The analyses were performed using Prism v.6.0 (Graphpad software Inc.). The statistical significance was considered as $\mathrm{p}<$ 0.05 . Data are represented as means \pm standard errors of means.

\section{Results}

As illustrated in Figure 1, serum ghrelin concentration was increased (one-way ANOVA test; F $(2,21)=3.542, \mathrm{p}=0.047$ ) by the administration of either domperidone or erythromycin compared to orally treated controls (post hoc LSD test; $p=0.032$ and $p=0.032$, respectively). Although Eryt group displayed a higher level of ghrelin than Dom group, the difference was not statistically significant (post hoc LSD test; $p>0.05$ ). There was no significant difference between enteral and parenteral control groups after receiving the respective vehicle (Student's t-test; $t=0.699$, $\mathrm{df}=14, \mathrm{p}=0.496)$ (Fig. 2A). In comparison to PCon animals, the administration of metoclopramide raised the circulating ghrelin levels (Student's t-test; $\mathrm{t}=2.539, \mathrm{df}=14, \mathrm{p}=0.024$ ), as depicted in Figure 2B. The multiple comparison of Met, Dom, and Eryt groups showed no statistically significant difference (one-way ANOVA test; $\mathrm{F}(2,21)=0.828, \mathrm{p}=0.451)$.

\section{Discussion}

Domperidone and metoclopramide, the antidopaminergic prokinetics, are commonly prescribed against a variety of intestinal motility disorders, as well as for the prevention of nausea and vomiting (5). In recent years, erythromycin, the first macrolide discovered, has been recommended to be used for its prokinetic properties, which is through cholinergic recruitment, although with cautions $(21,22)$. Additionally, ghrelin, an endogenous neuropeptide, is known to enhance the motility and so, ghrelin mimetics are proposed to be a novel line of the treatment strategy in intestinal motility disorders (23). However, to date, the interactions of the investigated prokinetics, namely domperidone, metoclopramide and erythromycin, with ghrelin secretion have remained occult. The results of the present study indicated a significant increase in ghrelin with both types of prokinetics.

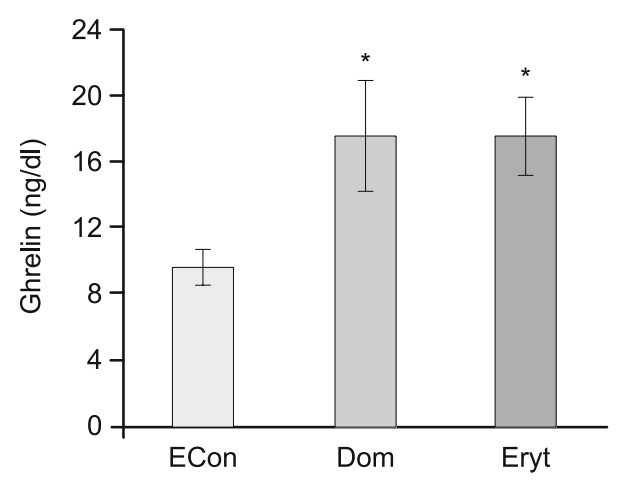

Fig. 1. The administration of either domperidone or erythromycin increased ghrelin concentrations. Asterisk (*) indicates the statistical significance $(p<0.05)$ versus control group. 

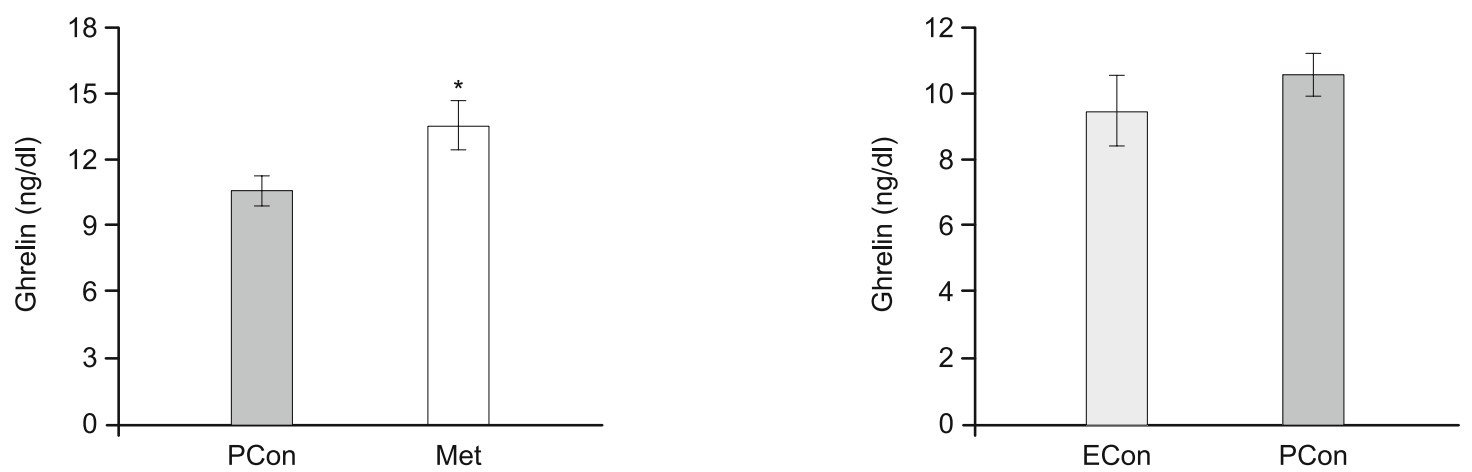

Fig. 2. (A) There was no statistically significant difference between enteral and parenteral controls (p $>0.05)$. (B) Compared to parenteral controls, the administration of metoclopramide resulted in an increase in ghrelin. Asterisk $(*)$ indicates the statistical significance $(p<0.05)$ versus control group.

Erythromycin occupies the motilin receptors in human, which enhances intestinal motility through the cholinergic activity (24). Because it is a well-established fact that acetylcholine provokes the increase in ghrelin (25), the relation between erythromycin and ghrelin can be anticipated in humans. On the other hand, rodents lack the motilin receptors (26). Nevertheless, several authors have reported a prokinetic feature of erythromycin in rodents $(27,28)$. The present study demonstrated an increase in circulating ghrelin with the erythromycin treatment, although the mechanism of this increase, which is needed to be explained in future studies, seems to be independent of the motilin receptors. In regard to the results with antidopaminergic prokinetics, taking a look at Parkinson's disease can be elucidatory, because it is a quintessential prototype for central dopaminergic deficiency. Although about a half of the patients suffering from Parkinson's disease experience reduced intestinal motility (29), it is likely because of decreased cholinergic and increased catecholaminergic stimulation (30), and dopaminergic medication (31). The study by Unger et al (32) pointed out the decrease in ghrelin signaling under this catecholaminergic and dopaminergic overstimulation, whereas it should be also noted that Karasawa et al (33) reported conflicting findings in a similar experimental Parkinsonism model. Interestingly, no change in fasting ghrelin in vagotomized patients (34) suggests that disturbed cholinergic transmission is not a determinant for lowered ghrelin levels in Parkinson's disease. Moreover, an in vitro study by Iwakura et al (18) demonstrated that dopamine stimulates the ghrelin release via $\mathrm{D}_{1}$ receptors in the mouse ghrelinoma cell line (MGN3-1). Since $\mathrm{D}_{1}$ and $\mathrm{D}_{2}$ receptors have antithetic characters as $\mathrm{D}_{2}$ receptor antagonists potentiate $\mathrm{D}_{1}$ receptor-associated events and vice versa in the CNS (35), the increment of ghrelin concentrations with $\mathrm{D}_{2}$ antagonists may be related to the enhancement of $\mathrm{D}_{1}$ receptor activity. It is of note that the interrelation of $\mathrm{D}_{1}$ and $\mathrm{D}_{2}$ receptors in this manner in the gastrointestinal system remains unknown. It is also not clear if intestinal dopamine influences ghrelin release in vivo; however, the facts that the ghrelin-producing cells are stimulated by low ambient D-glucose (36), and the intra-gastric infusion of nutrients provoke the increase in dopamine in the brain (37) may confer an indirect evidence for the interaction between dopamine and ghrelin in the gastrointestinal system. A simpler explanation of our results may depend on the ability of $\mathrm{D}_{2}$ stimulation to inhibit acetylcholine release (38). The antagonism of $\mathrm{D}_{2}$ receptors may result in the potentiation of cholinergic transmission, which leads to the increment of ghrelin secretion. Interestingly, Sudakov and Bashkatova (39) showed that domperidone increases the feeding behavior, although it cannot penetrate the blood-brain barrier. Their finding may be connected with the induction of ghrelin secretion by this antidopaminergic prokinetic. Conclusively, from this point, one can speculate that the inhibition of dopamine type 2 receptors may relieve the basal inhibitory effect of dopamin or may provoke the activity of dopamine type 1 receptors, and this subsequently leads to the increase in ghrelin. From a much more mechanistic view, the increase in ghrelin may be generated from stimulation of ghrelinproducing cells by smooth muscle contractions. To our results, it is not possible to make a deduction about whether the increase of ghrelin is a result of a direct effect on ghrelin-producing cells or an indirect effect arisen by dopamine antagonism. Nevertheless, this seminal study warrants further investigation of the relation between prokinetic dopamine antagonists and ghrelin.

Finally, the present study demonstrated that the levels of circulating ghrelin increase by the administration of antidopaminergic and cholinergic prokinetics. Hence, this effect on ghrelin may partly be responsible for the motility stimulating actions of domperidone, metoclopramide, and erythromycin.

\section{Learning points}

- The antidopaminergic prokinetics metoclopramide and domperidone increase the circulating levels of ghrelin.

- The stimulating effect of antidopaminergic prokinetics on ghrelin secretion is comparable to that of erythromycin.

\section{References}

1. Li ZS, Pham TD, Tamir H, Chen JJ, Gershon MD. Enteric dopaminergic neurons: definition, developmental lineage, and effects of extrinsic denervation. J Neurosci 2004; 24 (6): 1330-1339. 
2. Li ZS, Schmauss C, Cuenca A, Ratcliffe E, Gershon MD. Physiological modulation of intestinal motility by enteric dopaminergic neurons and the D2 receptor: analysis of dopamine receptor expression, location, development, and function in wild-type and knock-out mice. J Neurosci 2006; 26 (10): 2798-2807.

3. Pawlik W, Mailman D, Shanbour LL, Jacobson ED. Dopamine effects on the intestinal circulation. Am Heart J 1976; 91 (3): 325-331.

4. Walker JK, Gainetdinov RR, Mangel AW, Caron MG, Shetzline MA. Mice lacking the dopamine transporter display altered regulation of distal colonic motility. Am J Physiol Gastrointest Liver Physiol 2000; 279 (2): G311-G318.

5. Tonini M, Cipollina L, Poluzzi E, Crema F, Corazza GR, de Ponti F. Review article: clinical implications of enteric and central D2 receptor blockade by antidopaminergic gastrointestinal prokinetics. Aliment Pharmacol Ther 2004; 19 (4): 379-390.

6. Zizzo MG, Mulè F, Mastropaolo M, Serio R. D1 receptors play a major role in the dopamine modulation of mouse ileum contractility. Pharmacol Res 2010; 61 (5): 371-378.

7. Acosta A, Camilleri M. Prokinetics in gastroparesis. Gastroenterol Clin North Am 2015; 44 (1): 97-111.

8. Kojima M, Hosoda H, Date Y, Nakazato M, Matsuo H, Kangawa K. Ghrelin is a growth-hormone-releasing acylated peptide from stomach. Nature 1999; 402 (6762): 656-660.

9. Veldhuis JD, Bowers CY. Integrating GHS into the Ghrelin System. Int J Pept 2010; 2010.

10. Ozturk AS, Guzel M, Askar TK, Aytekin I. Evaluation of the hormones responsible for the gastrointestinal motility in cattle with displacement of the abomasum; ghrelin, motilin and gastrin. Vet Rec 2013; 172 (24): 636-636.

11. Sakata I, Sakai T. Ghrelin cells in the gastrointestinal tract. Int J Pept 2010; 2010 .

12. Muller TD, Nogueiras R, Andermann ML et al. Ghrelin. Mol Metab 2015; 4 (6): 437-460.

13. Edholm T, Levin F, Hellström PM, Schmidt PT. Ghrelin stimulates motility in the small intestine of rats through intrinsic cholinergic neurons. Regul Pept 2004; 121 (1-3): 25-30.

14. Masuda $\mathbf{Y}$, Tanaka $\mathrm{T}$, Inomata $\mathbf{N}$ et al. Ghrelin stimulates gastric acid secretion and motility in rats. Biochem Biophys Res Commun 2000; 276 (3): 905-908

15. Swartz EM, Browning KN, Travagli RA, Holmes GM. Ghrelin increases vagally mediated gastric activity by central sites of action. Neurogastroenterol Motil 2014; 26 (2): 272-282.

16. Mondal A, Aizawa S, Sakata I, Goswami C, Oda S-I, Sakai T. Mechanism of ghrelin-induced gastric contractions in Suncus murinus (house musk shrew): involvement of intrinsic primary afferent neurons. PloS one 2013; 8 (4): e60365.

17. Iwakura H, Kangawa K, Nakao K. The regulation of circulating ghrelin - with recent updates from cell-based assays. Endocr J 2015; 62 (2): 107-122.

18. Iwakura $H$, Ariyasu $H$, Hosoda $H$ et al. Oxytocin and dopamine stimulate ghrelin secretion by the ghrelin-producing cell line, MGN3-1 in vitro. Endocrinology 2011; 152 (7): 2619-2625.

19. de la Cour CD, Norlén P, Håkanson R. Secretion of ghrelin from rat stomach ghrelin cells in response to local microinfusion of candidate messenger compounds: a microdialysis study. Regul Pept 2007; 143 (1-3): 118-126.

20. Engelstoft MS, Park W-M, Sakata I et al. Seven transmembrane G protein-coupled receptor repertoire of gastric ghrelin cells. Mol Metab 2013; 2 (4): 376-392.
21. Camilleri M, Parkman HP, Shafi MA, Abell TL, Gerson L. Clinical Guideline: Management of Gastroparesis. Am J Gastroenterol 2013; 108 (1): 18-38.

22. Hawkyard CV, Koerner RJ. The use of erythromycin as a gastrointestinal prokinetic agent in adult critical care: benefits versus risks. J Antimicrob Chemother 2007; 59 (3): 347-358

23. Shin A, Wo JM. Therapeutic applications of ghrelin agonists in the treatment of gastroparesis. Curr Gastroenterol Rep 2015; 17 (2): 430.

24. Abell TL, Bernstein RK, Cutts T et al. Treatment of gastroparesis: a multidisciplinary clinical review. Neurogastroenterol Motil 2006; 18 (4): 263-283.

25. Broglio F, Gottero C, van Koetsveld Pet al. Acetylcholine regulates ghrelin secretion in humans. J Clin Endocrinol Metab 2004; 89 (5): 2429-2433.

26. Ohno T, Mochiki E, Kuwano H, Ohno T, Mochiki E, Kuwano H. The Roles of Motilin and Ghrelin in Gastrointestinal Motility. Int J Pept 2010; 2010 (2): 1-6.

27. Lim C-H, Choi M-G, Park H, Baeg MK, Park JM. Effect of DA-9701 on gastric emptying in a mouse model: assessment by ${ }^{13} \mathrm{C}$-octanoic acid breath test. World J Gastroenterol 2013; 19 (27): 4380-4385.

28. Shalaby MAF, Latif HAAE, Sayed MEE. Interaction of insulin with prokinetic drugs in STZ-induced diabetic mice. World J Gastrointest Pharmacol Ther 2013; 4 (2): 28-38.

29. Martinez-Martin P, Schapira AHV, Stocchi F et al. Prevalence of nonmotor symptoms in Parkinson's disease in an international setting; study using nonmotor symptoms questionnaire in 545 patients. Mov Disord 2007; 22 (11): 1623-1629.

30. Zheng L-F, Wang Z-Y, Li X-F et al. Reduced expression of choline acetyltransferase in vagal motoneurons and gastric motor dysfunction in a 6-OHDA rat model of Parkinson's disease. Brain Res 2011; 1420: 59-67.

31. Robertson DR, Renwick AG, Wood ND et al. The influence of levodopa on gastric emptying in man. Br J Clin Pharmacol 1990; 29 (1): 47-53.

32. Unger MM, Möller JC, Mankel K et al. Postprandial ghrelin response is reduced in patients with Parkinson"s disease and idiopathic REM sleep behaviour disorder: a peripheral biomarker for early Parkinson"s disease? J Neurol 2011; 258 (6): 982-990.

33. Karasawa H, Pietra C, Giuliano C et al. New ghrelin agonist, HM01 alleviates constipation and L-dopa-delayed gastric emptying in 6-hydroxydopamine rat model of Parkinson's disease. J Neurogastroenterol Motil 2014; 26 (12): 1771-1782.

34. Kamiji MM, Troncon LEA, Antunes-Rodrigues J, Elias LL, de Castro M, Oliveira RB. Ghrelin and PYY (3-36) in gastrectomized and vagotomized patients: relations with appetite, energy intake and resting energy expenditure. Eur J Clin Nutr 2010; 64 (8): 845-852.

35. Eyny YS, Horvitz JC. Opposing roles of D1 and D2 receptors in appetitive conditioning. J Neurosci 2003; 23 (5): 1584-1587.

36. Sakata I, Park W-M, Walker AK et al. Glucose-mediated control of ghrelin release from primary cultures of gastric mucosal cells. Am J Physiol Endocrinol Metab 2012; 302 (10): E1300-E1310.

37. de Araujo IE, Ferreira JG, Tellez LA, Ren X, Yeckel CW. The gutbrain dopamine axis: a regulatory system for caloric intake. Physiol Behav 2012; 106 (3): 394-399.

38. Benarroch EE. Enteric nervous system: functional organization and neurologic implications. Neurology 2007; 69 (20): 1953-1957.

39. Sudakov SK, Bashkatova VG. Effect of peripheral D (2) dopamine receptor antagonist domperidone on metabolism, feeding behavior, and locomotor activity of rats. Bull Exp Biol Med 2013; 155 (6): 705-707.

Received August 4, 2016. Accepted August 15, 2016. 